\title{
In situ immobilization on the silica gel surface and adsorption capacity of polymer-based azobenzene on toxic metal ions
}

\author{
Irina Savchenko ${ }^{1} \cdot$ Elina Yanovska ${ }^{1} \cdot$ Dariusz Sternik $^{2} \cdot$ Olga Kychkyruk $^{3} \cdot$ Lidiya Ol'khovik $^{1} \cdot$ Yana Polonska $^{1}$
}

Received: 14 December 2017 / Accepted: 20 March 2018

๑) Springer-Verlag GmbH Germany, part of Springer Nature 2018

\begin{abstract}
In situ immobilization of poly[(4-methacryloyloxy-(4'-carboxy)azobenzene] on silica gel surface has been performed by radical polymerization of monomer. The fact of polymer immobilization is confirmed by IR spectroscopy. TG and DSC-MS analysis showed that the mass of the immobilized polymer was $10.61 \%$. The SEM-microphotograph-synthesized composite analysis showed that the immobilized polymer on the silica gel surface is placed in the form of fibers. It has been found that the synthesized composite exhibits the sorption ability in terms of microquantities of $\mathrm{Cu}(\mathrm{II}), \mathrm{Cd}(\mathrm{II}), \mathrm{Pb}(\mathrm{II}), \mathrm{Mn}(\mathrm{II})$ and $\mathrm{Fe}(\mathrm{III})$ ions in a neutral aqueous medium. The quantitative sorption of microquantities of $\mathrm{Pb}$ (II) and $\mathrm{Fe}$ (III) ions has been recorded. It has been found that immobilization of the silica gel surface leads to an increase in its sorption capacitance for $\mathrm{Fe}(\mathrm{III}), \mathrm{Cu}(\mathrm{II})$ and $\mathrm{Pb}$ (II) ions by half.
\end{abstract}

Keywords Poly[(4-methacroyloxy-(4'-carboxy)azobenzene $] \cdot$ Modified silica $\cdot$ In situ immobilization $\cdot$ Adsorption properties $\cdot$ Composite $\cdot$ In situ immobilization $\cdot$ Heavy metals

$\begin{array}{ll}\text { Abbreviations } \\ \text { AIBN } & 2,2^{\prime} \text {-azobisisobutyronitrile } \\ \text { THF } & \text { tetrahydrofuran } \\ \text { IR } & \text { infrared spectroscopy } \\ \text { TG } & \text { thermogravimetry }\end{array}$

Irina Savchenko iras@univ.kiev.ua

Elina Yanovska

elina_yanovska@ukr.net

Dariusz Sternik

dsternik@hektor.umcs.lublin.pl

Olga Kychkyruk

panova_o_yu@ukr.net

Lidiya Ol'khovik

iras_savchenko@mail.ru

Yana Polonska

yana.buryachenko.93@gmail.com

1 Taras Shevchenko National University of Kyiv, 12 L. Tolstogo St, Kiev 01033, Ukraine

2 Maria Curie-Sklodowska University, pl. Maria Curie-Sklodowskiej 3, 20-031 Lublin, Poland

3 Ivan Franko Zhytomyr State University, 40 Velyka Berdychivska St, Zhytomyr 10008, Ukraine
DSC-MS differential scanning calorimetry-mass spectrometry

DTA differential thermal analysis

\section{Introduction}

In recent years, the preparation of organic/inorganic hybrid materials composed of organic polymers and silica nanoparticles has been widely investigated. The combination of organic polymer components with nanometer-sized silica fillers in a single material has extraordinary significance for the development of hybrid materials with unique properties (Draxl et al. 2014; Peveler et al. 2014; Yang et al. 2007; Tamaki et al. 1997).

The modification of the surface of porous inorganic materials by nitrogen-containing polymers allows to obtain sorbents for removing toxic metals from the waste water due to their complexation with nitrogen atoms of immobilized polymer (Yanovska et al. 2007; Wan Ngah et al. 2012; Dadashev et al. 2016; Karthik and Meenakshi 2014; Budnyak et al. 2015).

One of the promising ways of creating organo-mineral composite materials with valuable sorption properties is polymerization or in situ immobilization, which consists in the direct formation of an immobilized polymeric layer in 
the presence of particles of inorganic matrix (Ryabchenko et al. 2014; Ryabchenko et al. 2016; Yanovska et al. 2017).

The advantages of this method of fixing a polymer on a solid surface in comparison with physical adsorption of pre-synthesized polymers are optimal (both energetic and geometric) location of macromolecules on a solid surface, which strengthens the fixation of a polymer on an inorganic matrix. This arrangement of macromolecules creates additional possibilities for the regeneration of the obtained composite material as a sorbent in multiple applications, and the possibility of self-organization of polymer chains in supramolecular structures on the surface of an inorganic matrix, the presence of which increases the sorption capacity of the composite (Sapurina and Stejskal 2008; Sowa et al. 2012). Compared to the chemical bonding of pre-synthesized polymers, in situ immobilization is characterized by the absence of the residues of monomolecular compounds on the solid surface of the matrix, which were used as bridging groups between the inorganic matrix and the polymer.

All this leads to expansion of the range of immobilized polymer adsorption ability and improve its adsorption capacity.

This work is devoted to the in situ immobilization of poly[(4-methacroyloxy-(4'-carboxy)azobenzene] on the silica gel surface, and adsorption properties of the synthesized composite material on ions $\mathrm{Pb}(\mathrm{II}), \mathrm{Cd}(\mathrm{II}), \mathrm{Mn}(\mathrm{II}), \mathrm{Cu}$ (II) and $\mathrm{Fe}(\mathrm{III})$.

\section{Materials and methods}

For the study, the silica gel produced by Merck, whose surface parameters are given in Table 1, were used.

\section{Synthesis of 4-hydroxy-(4'-carboxy)-azobenzene}

4-aminobenzoic acid $(0.1 \mathrm{~mol})$ was dissolved in a solution of concentrated hydrochloric acid:water (50:50) $(100 \mathrm{~mL})$. The mixture was cooled to $0{ }^{\circ} \mathrm{C}$ in an ice-water bath, and then sodium nitrite $(0.1 \mathrm{~mol})$ dissolved in a small amount of water added dropwise. The reaction mixture was stirred for $2 \mathrm{~h}$, and then phenol $(0.1 \mathrm{~mol})$ in $\mathrm{NaOH}$ solution $(100 \mathrm{~mL})$ was added slowly. The resultant solution was stirred for $4 \mathrm{~h}$ at $0-5{ }^{\circ} \mathrm{C}$ and for an additional $10 \mathrm{~h}$ at room temperature. The precipitate formed was collected by vacuum filtration and finally dried. The product was purified by recrystallization from ethanol. Yield: 87-92\%.

\section{4-hydroxy-(4'-carboxy)-azobenzene}

${ }^{1} \mathrm{H}$ NMR (400 MHz, DMSO, $\delta$, ppm): 7.93-6.89 (3d, s, 7H, $\mathrm{Ph}-\mathrm{H}), 11.4$ (s, 1H, COOH), 10.19 (s, 1H, OH).

The synthesis of 4-methacryloyloxy-(4'-carboxy)azobenzene, is given below: azocompound $(2.58 \mathrm{~g}$, $0.01 \mathrm{~mol}$ ) was dissolved in $25 \mathrm{~mL}$ anhydrous THF, and freshly distilled triethylamine $(1.53 \mathrm{~mL}, 0.011 \mathrm{~mol})$ was added to the solution. The reaction mixture was then cooled to $0-5{ }^{\circ} \mathrm{C}$. Methacryloyl chloride $(1.07 \mathrm{~mL}, 0.011 \mathrm{~mol})$ in THF $(5 \mathrm{~mL})$ was injected gradually to the above solution via a glass syringe, while the solution temperature was kept below $5{ }^{\circ} \mathrm{C}$. The reaction mixture was stirred overnight at room temperature. The resulting precipitate was filtered off. Purification was followed by recrystallization from methanol. Yield: $63-76 \%$.

\section{4-methacryloyloxy-(4'-carboxy)-azobenzene}

${ }^{1} \mathrm{H}$ NMR (400 MHz, DMSO, $\delta$, ppm): 8.12-6.92 (3d, s, 7H, Ph-H), 11.3 (s, 1H, COOH), 6.28 (s, $1 \mathrm{H} \mathrm{C}=\mathrm{CH}_{2}$, cis), 5.82 (s, $1 \mathrm{H} \mathrm{C}=\mathrm{CH}_{2}$, trans), $2.06\left(\mathrm{~s}, 3 \mathrm{H},=\mathrm{C}-\mathrm{CH}_{3}\right)$.

The polymerization of 4-methacryloyloxy-(4'-carboxy)azobenzene in the presence of silica (fraction of particles with a diameter of $0.1-0.2 \mathrm{~mm}$, specific surface $428 \mathrm{~m}^{2} / \mathrm{g}$, Merck) has been carried out under the argon atmosphere. A solution of $3.5 \mathrm{~g}$ 4-methacryloyloxy-(4'-carboxy)azobenzene and $0.175 \mathrm{~g}$ of 2,2'-azobisisobutyronitrile (AIBN) in $80 \mathrm{~mL}$ tetrahydrofuran (THF) were poured into a flask containing $15 \mathrm{~g}$ of silica gel. When argon blowing was finished after $15 \mathrm{~min}$, the reaction mixture was heated to $68{ }^{\circ} \mathrm{C}$; polymerization continued for $6 \mathrm{~h}$ with stirring. The reaction was stopped by cooling the reaction mixture. The resulting suspension was poured into a porcelain cup and left overnight to evaporate the solvent; the synthesized composite was washed three times with isopropyl alcohol, filtered and air-dried for $24 \mathrm{~h}$ at room temperature.

\section{Solutions with different $\mathrm{pH}$ values}

To create $\mathrm{pH} 4.0$, a standard buffer solution was prepared using a titration substance (ISO 8135: 2009,
Table 1 Characteristics of the surface of silica gel and synthesized composite

\begin{tabular}{llllll}
\hline Object of study & \multicolumn{2}{l}{ Surface area, $\left(\mathrm{m}^{2} / \mathrm{g}\right)$} & $\begin{array}{l}\text { Average pore } \\
\text { volume }\left(\mathrm{cm}^{3} / \mathrm{g}\right)\end{array}$ & $\begin{array}{l}\text { Average } \\
\text { pore size, } \\
(\mathrm{nm})\end{array}$ \\
\cline { 2 - 5 } & $\mathrm{P} / \mathrm{P}_{0}$ & $\mathrm{BET}$ & Langmuir & & 5,9194 \\
\hline Silica gel & 446,9738 & 463,5319 & 686,9092 & 0,6860 & 6,0365 \\
The synthesized composite & 385,7589 & 402,1408 & 599,7788 & 0,6069 & 6 \\
\hline
\end{tabular}


manufacturer-JSC “Kyiv Plant RIAP”). pH 1.0 was created by adding $0.1 \mathrm{M} \mathrm{HCl}, \mathrm{pH} 2.5$-by adding $0.1 \mathrm{M}$ acetic acid. Acid solutions were prepared from fixants. The exact $\mathrm{pH}$ of the working solutions was determined using a $\mathrm{pH}$ meter "Hanna Combo pH/EC/TDS/Temp tester Model HI98129 low range".

FTIR spectra of the samples of composite and the silica were recorded using an IR spectrometer with Fourier transformation (Thermo Nicolet Nexus FT-IR, USA). For this purpose, the samples were ground in an agate mortar and pressed with $\mathrm{KBr}$. The FTIR spectra were recorded in the spectral range of $500-4000 \mathrm{~cm}^{-1}$ with 16 scans per spectrum at a resolution of $4 \mathrm{~cm}^{-1}$.

\section{Thermal analysis}

Thermal analysis was carried out on a STA 449 Jupiter F1, Netzsch (Germany) under the following operational conditions: heating rate of $10{ }^{\circ} \mathrm{C} \mathrm{min}^{-1}$, dynamic atmosphere of synthetic air $\left(50 \mathrm{~mL} \mathrm{~min}^{-1}\right)$, temperature range of $30-950{ }^{\circ} \mathrm{C}$, sample mass $\sim 18 \mathrm{mg}$, sensor thermocouple type $\mathrm{S}$ TG-DSC. As a reference, empty $\mathrm{Al}_{2} \mathrm{O}_{3}$ crucible was used. The gaseous products emitted during decomposition of material were analyzed by QMS 403C Aeölos (Germany) coupling on-line to STA instrument. The QMS data were gathered in the range from 10 to $160 \mathrm{amu}$.

\section{Surface morphology analysis}

The surface morphology of composite was observed using a scanning electron microscope (SEM, LEO 1430VP, Carl Zeiss, Germany).

\section{The investigations of adsorption properties}

The investigations of adsorption properties of the obtained composite with respect to $\mathrm{Pb}$ (II), $\mathrm{Cd}$ (II), $\mathrm{Mn}$ (II), $\mathrm{Cu}$ (II) and $\mathrm{Fe}(\mathrm{III})$ ions were carried out in the static mode with periodic hand stirring. For that, the sample of $0.1 \mathrm{~g}$ of synthesized adsorbent was contacted with $25 \mathrm{~mL}$ of solutions at different concentrations of nitrates of the chosen metals. Working nitrate solutions of $\mathrm{Pb}$ (II), $\mathrm{Cd}(\mathrm{II}), \mathrm{Mn}$ (II), $\mathrm{Cu}$ (II) and $\mathrm{Fe}(\mathrm{III})$ are prepared with the sets of "standard sample solutions" of these salts on $1 \mathrm{M} \mathrm{HNO}_{3}$ background (produced by A.V. Bogatsky FHI in Odesa) with concentrations of 1 and $10 \mathrm{mg} /$ $\mathrm{mL}$.

Determination of the equilibrium concentration of the metals was carried out by atomic absorption using a flaming atomic absorption spectrophotometer "Saturn" (Ukraine) in a "air-propane-butane" flame mixture. Maxima wavelengths were: $324.7 \mathrm{~nm}$ for $\mathrm{Cu}(\mathrm{II}), 228.8 \mathrm{~nm}$-for $\mathrm{Cd}(\mathrm{II})$, $283.3 \mathrm{~nm}$-for $\mathrm{Pb}$ (II), $248.3 \mathrm{~nm}$-for $\mathrm{Fe}(\mathrm{III})$, aperture being $0.5 \mathrm{~cm}$ wide.

The degree of adsorption $(R)$ is calculated using the formula:

$R=\left(m_{\text {ads }} / m_{\mathrm{o}}\right) \cdot 100 \%=\left(m_{\mathrm{o}}-m\right) / m_{\mathrm{o}} \cdot 100 \%$

where $m_{\mathrm{o}}$-mass of metal in the output solution, $m_{\mathrm{ads}}-$ mass of adsorbed metal, $m$-mass of metal in the equilibrium solution after adsorption, which is calculated as $m=[\mathrm{M}] \cdot V$, where [M]—equilibrium concentration of metal and $V-$ volume of equilibrium solution.

\section{Results and discussion}

The chemical structure of in situ polymer immobilization 4-methacryloyloxy-(4'-carboxy)-azobenzene on the silica surface could be presented as follows (Fig. 1).

The fact of the process of in situ polymerization and fixing of the polymer on the silica surface were confirmed by comparative analysis of IR spectra of synthesized composite, monomer and original silica gel (Fig. 2). Comparative analysis of the infrared spectra of the synthesized composite, silica gel and monomer (Fig. 2) shows that in contrast to the original silica gel, the absorption bands in the spectrum of the composite are in the range 2870-2845 $\mathrm{cm}^{-1}$, which correspond to symmetric valence vibrations
Fig. 1 The scheme of in situ immobilization of poly4methacryloyloxy-(4'-carboxy)azobenzene on the silica gel surface
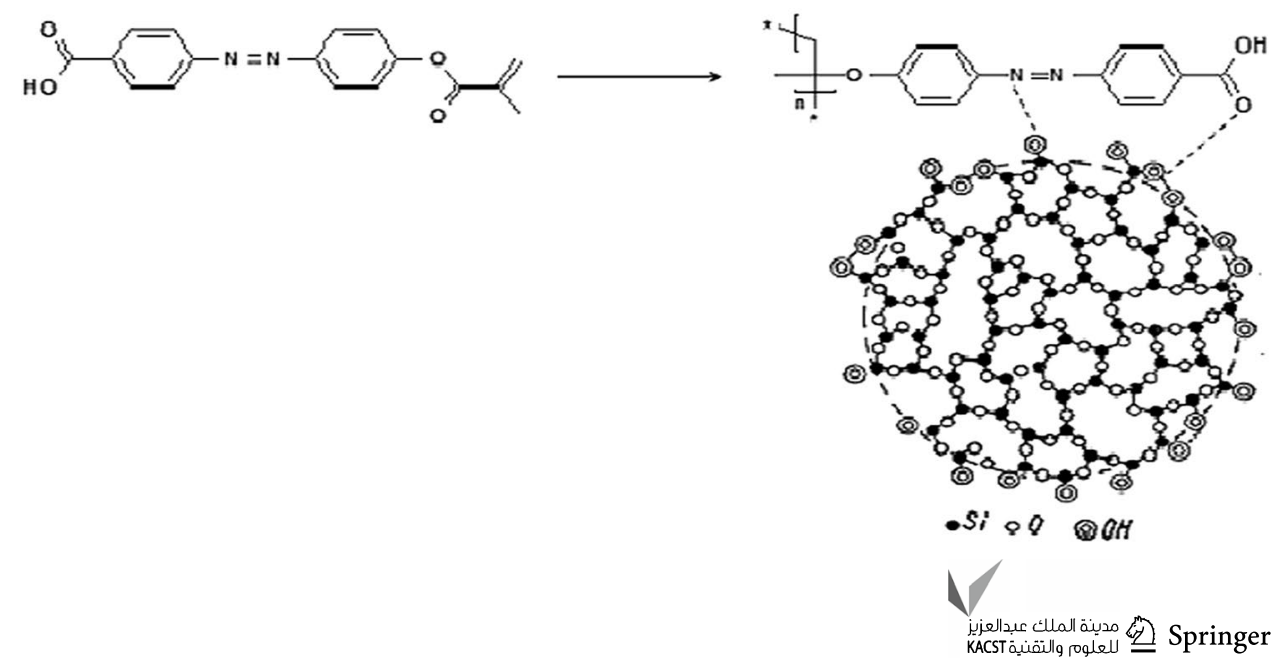
Fig. 2 The FTIR-spectra of the original silica gel (1) monomer (3) and synthesized composite (2)

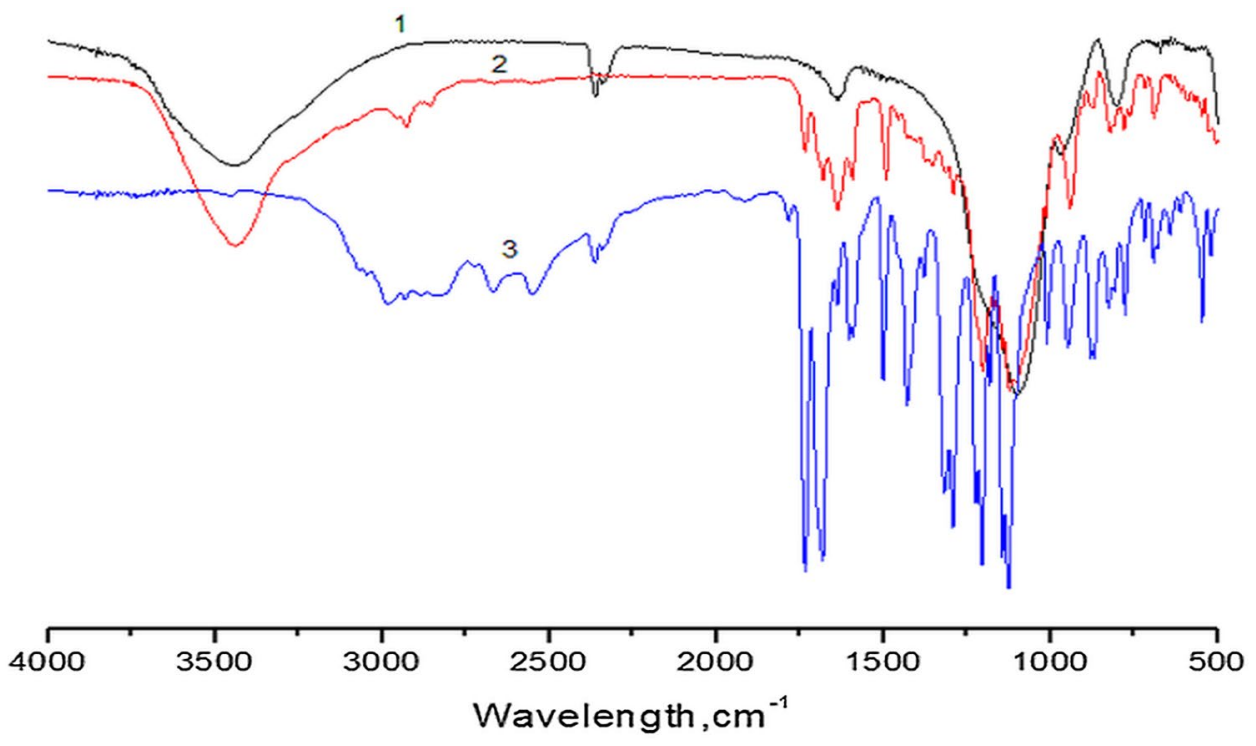

of the $\mathrm{sp}^{3}$ Hybridized Carbon of polymer in the groups $\mathrm{CH}$. These same bands are present in the IR spectrum of a monomer in the region of $2910-2850 \mathrm{~cm}^{-1}$. Absorption bands in the region $1700-1680 \mathrm{~cm}^{-1}$ are present in the spectra of monomer and polymer and correspond to valence vibrations of the $\mathrm{CO}$ in aromatic carboxylic acids. A number of lanes at 1600-1575 and 1525-1475 $\mathrm{cm}^{-1}$ can be attributed to the valence vibrations of the $\mathrm{C}-\mathrm{C}$ of the aromatic system. Weak absorption bands in the region 1500-1400 $\mathrm{cm}^{-1}$ correspond to the valence vibrations $\mathrm{N}=\mathrm{N}$ and are observed in the spectra of monomer and polymer. The bands at $1465-1440 \mathrm{~cm}^{-1}$ can be interpreted as the deformation of the $\mathrm{C}-\mathrm{H}$ fluctuations in the polymer chain, and the bands at $1440-1410 \mathrm{~cm}^{-1}$ relate to the valence fluctuations- $\mathrm{N}=\mathrm{N}$-azo group (Smith 1982; Tarasevich 2012). Consequently, the results of IR spectroscopy confirm the presence of a polymer on the surface of silica gel.
The influence of polymeric coating on thermal properties of silica were studied by conducting TG and DSC-MS analysis.

Figures 3 and 4 show the thermograms of the original silica gel and the synthesized composite.

The comparative analysis of the thermograms (Figs. 3 and 4) shows that the main loss of the composite mass due to the thermal decomposition of the immobilized polymer occurs in the range from 100 to $600{ }^{\circ} \mathrm{C}$. Loss of the composite mass is $16 \%$ generally. Taking into account that the mass loss of the original silica gel at this temperature range is $5.39 \%$, it can be argued that the mass fraction of the immobilized polymer in the synthesized composite is $10.61 \%$. Thus, the reaction yield is $50 \%$.

Figure 5 shows a thermogram of a synthesized composite, combined with a mass spectrum in 3D format (Fig. 5a) and a mass spectrum in 2D format (Fig. 5b). Mass spectral studies show that, as a result of thermal degradation of a
Fig. 3 TG-, DTG-, DSC-curves of the silica

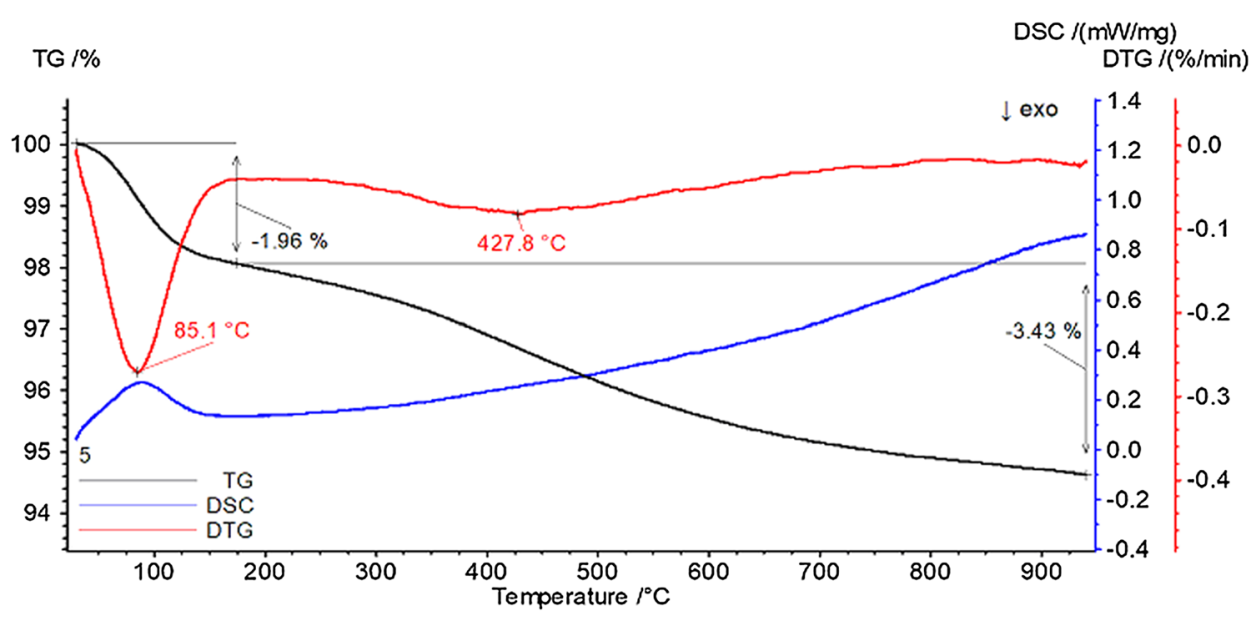


Fig. 4 TG-, DTG-, DSC-curves of the synthesized composite

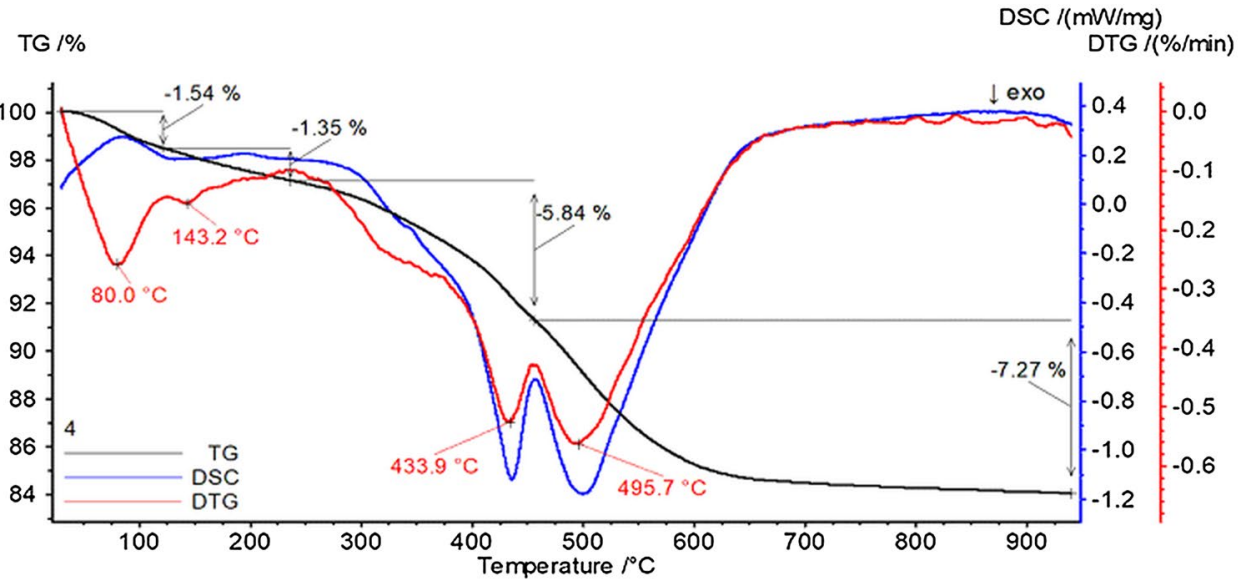

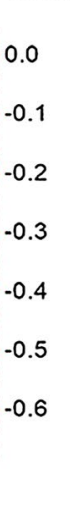

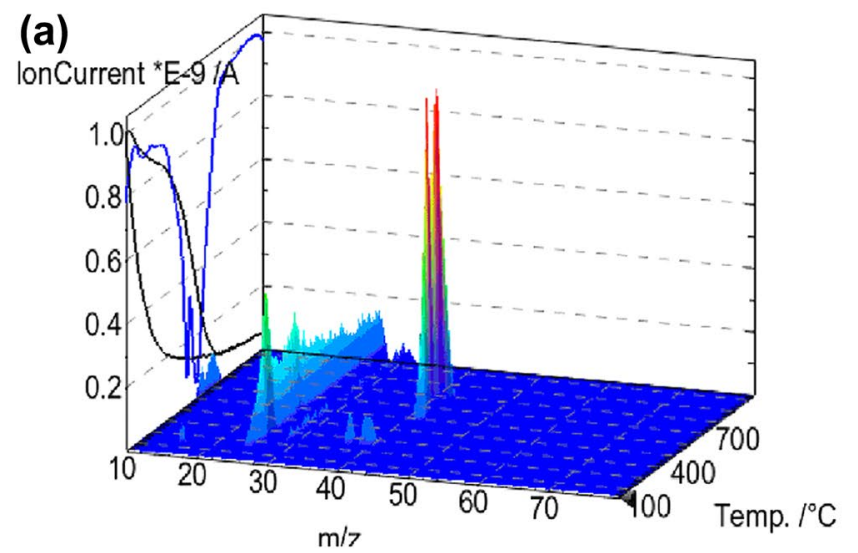

(b) lonCurrent *E-9/A

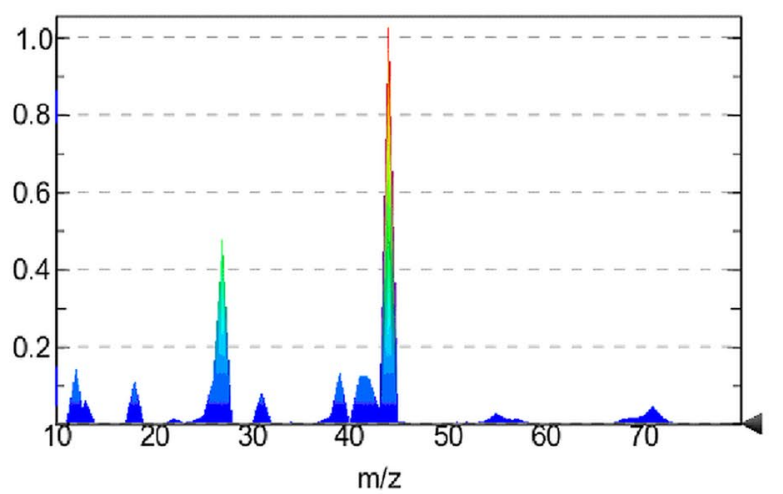

Fig. 5 Mass spectrum DSC-QMS-3D (a) and mass spectrum QMS-2D (b) of the synthesized composite

polymer at temperatures above $400{ }^{\circ} \mathrm{C}$, particles with a mass of 18, 28 and $44 \mathrm{Da}$ are most likely formed, which most likely correspond to the formation of water, nitrogen and $\mathrm{CO}_{2}$. In the temperature range of $200-400{ }^{\circ} \mathrm{C}$, the formation of a small number of particles with molecular masses 54 and 70, which most likely correspond to fragments of the carbon chain of a polymer.

Table 1 shows the main parameters of the surface of the original silica gel and the synthesized composite, namely the value of the specific area of the surface, calculated by different methods with the data of the sorption-desorption nitrogen isotherms, the mean pore volume and average pore size, found from the pore distribution curves in the investigated samples. As it follows from Table 1, the fixation of this polymer on the surface of the silica gel results in a slight decrease in the surface area, which is logical when placed on a porous surface of silica gel of non-porous polymer. But the average size and volume of pores thus change insignificantly, which suggests that the structure of the surface of the original silica gel at the same time does not change practically.
To clarify the geometrical shapes and geometric location of the CEM-microphotographs of synthesized composite at $50,000 \times(a), 100,000 \times$ (b) magnification-immobilized polymer on the surface of the silica gel, (Fig. 6) was received. As can be seen from Fig. 6, the immobilized polymer on the surface of the silica gel is placed in the form of fibers, and not globules.

The synthesized composite should detect the sorption ability of metal ions due to the complex activity of nitrogen atoms of azo groups and oxygen atoms of carboxylic groups. To confirm these considerations, we investigated the sorption of $\mathrm{Cu}$ (II) and $\mathrm{Fe}(\mathrm{III})$ ions, which have a high affinity for nitrogen-containing ligands (Skopenko and Savranskij 2004). In addition, the sorption of ions of toxic metals such as $\mathrm{Cd}$ (II), $\mathrm{Pb}(\mathrm{II})$ and $\mathrm{Mn}(\mathrm{II})$, which form complexes with oxygen atoms predominantly, was studied (Skopenko and Savranskij 2004).

The dependence of the adsorption degree of $\mathrm{Cu}$ (II), $\mathrm{Cd}$ (II), $\mathrm{Pb}(\mathrm{II}), \mathrm{Mn}(\mathrm{II})$ and $\mathrm{Fe}(\mathrm{III})$ ions by poly-4methacryloyloxy-(4'-carboxy) azobenzene, in situ immobilized on silica surface, from the acidity of the medium in the 

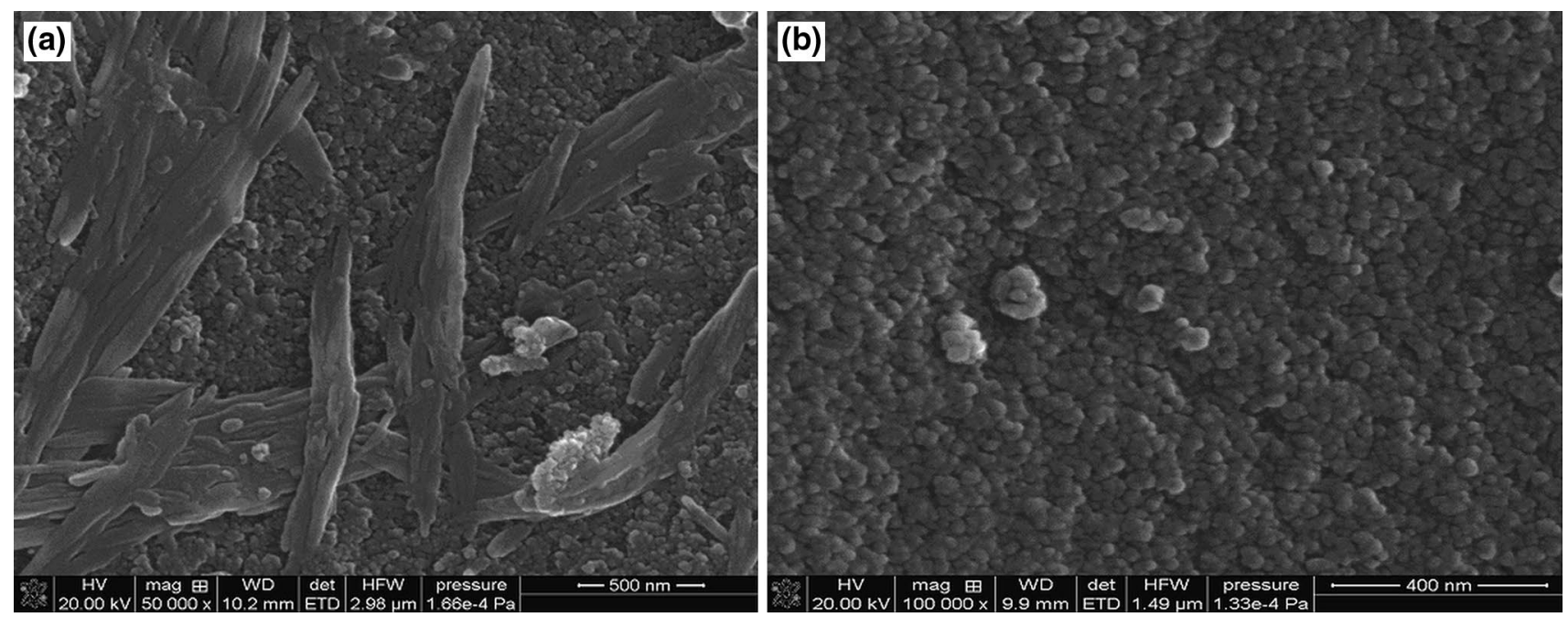

Fig. 6 SEM-microphotographs of synthesized composite at $50000 \times(\mathbf{a}), 100000 \times(\mathbf{b})$ magnification

Table 2 The degree of adsorption of $\mathrm{Cu}(\mathrm{II}), \mathrm{Cd}(\mathrm{II}), \mathrm{Pb}(\mathrm{II}), \mathrm{Mn}(\mathrm{II})$ and $\mathrm{Fe}(\mathrm{III})$ ions by poly[(4-methacryloyloxy-(4'-carboxy)azobenzene], in situ immobilized on silica surface, as a function of the medium acidity and the chemical composition of the medium

\begin{tabular}{|c|c|c|c|c|}
\hline \multirow[t]{2}{*}{ Ions } & \multicolumn{4}{|c|}{ Degree of adsorption $(R, \%)$} \\
\hline & $\mathrm{pH} 1.0(\mathrm{HCl})$ & $\begin{array}{l}\mathrm{pH} 2.5 \\
\left(\mathrm{CH}_{3} \mathrm{COOH}\right)\end{array}$ & $\begin{array}{l}\mathrm{pH} 4.0 \\
\text { phthalate } \\
\text { buffer }\end{array}$ & Distilled water \\
\hline $\mathrm{Cu}(\mathrm{II})$ & 0 & 0.3 & 5.1 & 76.6 \\
\hline $\mathrm{Cd}(\mathrm{II})$ & 0 & 0 & 0 & 41.0 \\
\hline $\mathrm{Pb}(\mathrm{II})$ & 4.4 & 26.8 & 24.2 & 100.0 \\
\hline $\operatorname{Mn}(\mathrm{II})$ & 0 & 5.4 & 0.2 & 44.3 \\
\hline $\mathrm{Fe}(\mathrm{III})$ & 17.3 & 93.8 & 32.5 & 100.0 \\
\hline
\end{tabular}

Experimental conditions: mass of sorbent- $0.1 \mathrm{~g}$, volume of solution- $25 \mathrm{~mL}, \mathrm{~m}_{\mathrm{M}}{ }^{0}-100 \mu \mathrm{g}$

static mode of adsorption presented in Table 2. The analysis of Table 2 shows that the synthesized composite as a whole exhibits the best sorption properties of the microquantities of the selected ions in the aqueous medium (without the addition of any buffer solutions), where it quantitatively adsorbs the ions of $\mathrm{Pb}$ (II) and $\mathrm{Fe}(\mathrm{III})$ and removes as much as all other investigated ions of metals possible in comparison with acidic medium.

It should be noted that in the alkaline medium, the polymer is washed away from the surface of silica gel, therefore, the study of sorption properties was carried out in acidic and neutral media only. The acid medium was formed with chloride, acetic acid and phthalate buffer.

At the same time, in the initial solutions of transition metals, chloride, acetate and phthalate complexes could be formed, respectively. In the process of sorption, these complexes interacted with immobilized polymer molecules

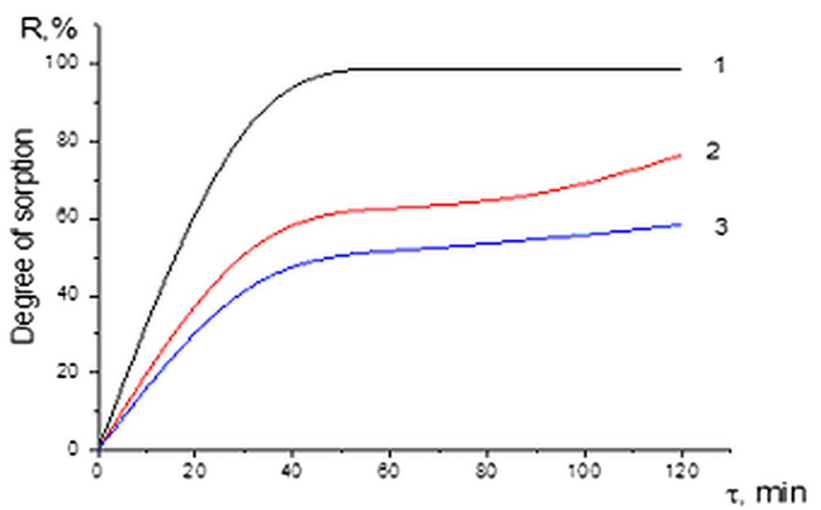

Fig. 7 Dependence of the degree of sorption from contact time in the static mode of nitrates $\mathrm{Pb}$ (II) $-1, \mathrm{Cu}$ (II) $-2, \mathrm{Fe}$ (III) - 3

with the formation on solid surfaces of multi-ligand complexes, whose stability constants for a single metal can vary greatly, which affects the degree of its sorption.

This phenomenon is observed in the sorption of Fe(III) ions. Thus, from Table 2, it is seen that the acetate complexes of ferrum (III) are sorted almost completely with the surface of the synthesized composite, while phthalate complexes are sorted one-third only in the analogous conditions of the experiment.

Taking into account the results of the studies presented in Table 2, further investigations of the sorption properties of the synthesized composite were carried out with aqueous solutions of the nitrates of the selected metals only.

Figure 7 shows the dependence of the degree of sorption from static contact time for $\mathrm{Pb}$ (II), $\mathrm{Cu}$ (II) and $\mathrm{Fe}(\mathrm{III})$ ions. As can be seen from this figure, the maximum degree of sorption of ions $\mathrm{Pb}(\mathrm{II})$ is achieved within $1 \mathrm{~h}$ of contact, 
while for $\mathrm{Cu}$ (II) and $\mathrm{Fe}(\mathrm{III})$ ions the equilibrium is established within a day.

Such a long period of determination of sorption equilibrium is typical of polymer sorbents. Thus, the obtained results confirm indirectly that sorption of metal ions occurs due to chemical interaction with immobilized polymer, and, unfortunately, indicate that this composite cannot be used effectively for sorption of ions of the corresponding metals in a dynamic mode.

To establish and compare the values of the sorption capacitance of the synthesized composite and the original silica gel with respect to $\mathrm{Cu}(\mathrm{II}), \mathrm{Pb}(\mathrm{II})$ and $\mathrm{Fe}(\mathrm{III})$ ions, the sorption isotherms of each individual ion from aqueous solutions of nitrates of these metals (without the addition of any buffer solutions) in static mode were constructed and compared with those for the original silica gel. It turned out that the isotherms of sorption of all-investigated metals belong to the $2 \mathrm{~L}$-species (Fig. 8), which indicates the uniform distribution of metal ions on the surface of the composite. This type of isotherm is typical for silica matrices, modified by complex-forming substances (Zaitsev 1997).

All obtained isotherms allow to calculate the adsorption capacity of the composite for each of the investigated ions.

The comparison of the sorption capacitance values of the synthesized composite and the original silica gel with respect to $\mathrm{Cu}(\mathrm{II}), \mathrm{Pb}(\mathrm{II})$ and $\mathrm{Fe}(\mathrm{III})$ ions calculated from the data processing of adsorption isotherms is given in Table 3 .

Comparing the results of studies on the sorption capacity of the formed composite and the original silica gel according to the data of this table, it can be argued that the sorption capacity of the composite for all these ions is twice as high as for the original silica gel.

However, comparing the values of the sorption capacity with the results of thermogravimetric and SEM analysis, it can be noted that, notwithstanding the linear position of the

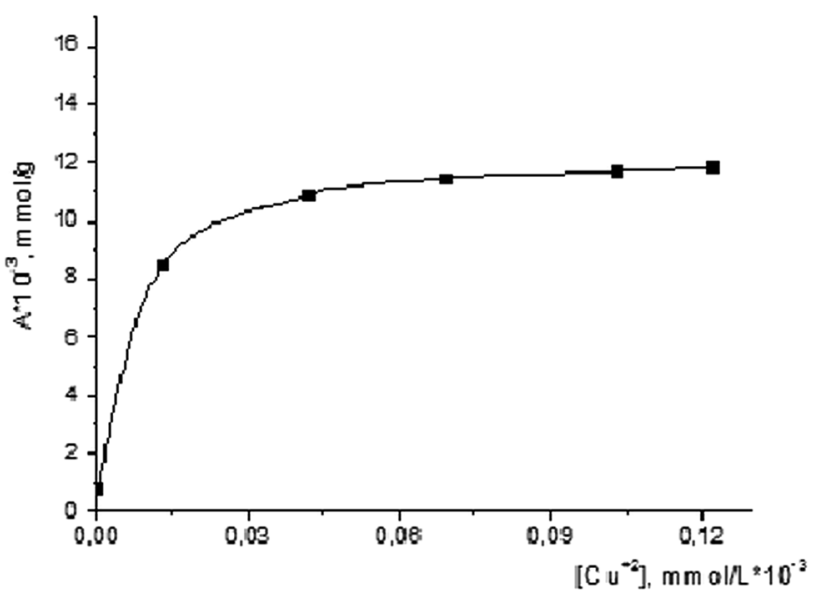

Fig. 8 Isotherm sorption $\mathrm{Cu}(\mathrm{II})$ on the surface of the synthesized composite
Table 3 Comparison of the adsorption capacity of the silica and the synthesized composite in relation to $\mathrm{Cu}(\mathrm{II}), \mathrm{Pb}$ (II) and $\mathrm{Fe}(\mathrm{III})$ ions in the static mode

\begin{tabular}{|c|c|c|c|c|}
\hline \multirow[t]{3}{*}{ Ion } & \multicolumn{4}{|c|}{ Adsorption capacity } \\
\hline & \multicolumn{2}{|l|}{ Silica } & \multicolumn{2}{|c|}{$\begin{array}{l}\text { Synthesized com- } \\
\text { posite }\end{array}$} \\
\hline & $\mathrm{mmol} / \mathrm{g}$ & $\mathrm{mg} / \mathrm{g}$ & $\mathrm{mmol} / \mathrm{g}$ & $\mathrm{mg} / \mathrm{g}$ \\
\hline $\mathrm{Fe}(\mathrm{III})$ & 0.008 & 0.45 & 0.016 & 0.89 \\
\hline $\mathrm{Pb}(\mathrm{II})$ & 0.002 & 0.41 & 0.0048 & 1.00 \\
\hline $\mathrm{Cu}(\mathrm{II})$ & 0.006 & 0.38 & 0.012 & 0.76 \\
\hline
\end{tabular}

Experimental conditions: mass of sorbents $-0.1 \mathrm{~g}$, volume of solution-25 mL, contact time in static mode-day

polymer on the surface of the silica gel, not all of its complexing centers were active in the interaction with the ions of the investigated metals, even under the optimal sorption conditions. The reason for this phenomenon is still unclear to us. Accordingly, the sorption capacity of the synthesized material in relation to the investigated ions is not sufficient for its practical use as a sorbent of these ions.

\section{Conclusions}

A new organo-mineral composite material has been synthesized by in situ immobilization of poly[(4-methacryloyloxy(4'-carboxy)azobenzene] on the silica gel surface by polymerization of the 4-methacryloyloxy-(4'-carboxy)azobenzene in the presence of 2,2'-azobisisobutyronitrile as the initiator of radical polymerization. The fact of heterophase polymerization has been confirmed by IR spectroscopy. As a result of thermogravimetric analysis and DSC-MS analysis, it has been found that the composition of synthesized composite includes $1061 \mathrm{wt} \%$ of polymer. The analysis of SEMmicrophotographs of synthesized composite showed that immobilized polymer on the surface of silica gel is placed in the form of fibers, not globules. As a result of studies on the sorption ability of the synthesized composite for $\mathrm{Cu}(\mathrm{II})$, $\mathrm{Cd}(\mathrm{II}), \mathrm{Pb}$ (II), $\mathrm{Mn}$ (II) and $\mathrm{Fe}(\mathrm{III})$ ions, it was recorded that the synthesized composite as a whole exhibits the best sorption properties relative to the microcavities of the selected ions in the neutral aqueous medium (without the addition of any buffer solutions), where it quantitatively adsorbs the number of ions of $\mathrm{Pb}(\mathrm{II})$ and $\mathrm{Fe}(\mathrm{III})$ and maximally removes all other investigated metal ions compared to the acidic medium. It was found that the maximum degree of sorption of ions $\mathrm{Pb}(\mathrm{II})$ is achieved within $1 \mathrm{~h}$ of contact, and for the $\mathrm{Cu}(\mathrm{II})$ and $\mathrm{Fe}(\mathrm{III})$ ions the equilibrium is established within a day. According to the results of data processing, sorption isotherms have shown that the immobilization of the surface of silica gel leads to an increase in its sorption capacity 
relative to $\mathrm{Fe}(\mathrm{III}), \mathrm{Cu}$ (II) and $\mathrm{Pb}$ (II) ions by half. However, the sorption capacity of the synthesized material in relation to the investigated ions is not sufficient for its practical use as a sorbent of these ions.

Acknowledgements The research leading to these results was financed from the People Programme (Marie Curie Actions) of the European Union's Seventh Framework Programme FP7/2007-2013/under REA Grant agreement N PIRSES-GA-2013-612484.

\section{References}

Budnyak T, Tertykh V, Yanovska E, Kołodynska D, Bartyzel A (2015) Adsorption of $\mathrm{V}(\mathrm{V}), \mathrm{Mo}(\mathrm{VI})$ and $\mathrm{Cr}(\mathrm{VI})$ oxoanions by chitosansilica composite synthesized by Mannich reaction. Adsorpt Sci Technol 6-8:645-657

Dadashev A, Tertykh V, Yanovska E, Yanova K (2016) New approach to synthesis of silica with chemically bound guanidine hydrochloride for preconcentration of metal ions. Am J Anal Chem 7:411-420

Draxl C, Nabok D, Hannewald K (2014) Organic/inorganic hybrid materials: challenges for ab initio methodology. Acc Chem Res 47(11):3225-3232

Karthik R, Meenakshi S (2014) Removal of hexavalent chromium ions using polyaniline/silica gel composite. J Water Process Eng $1: 37-45$

Peveler JW, Bear JC, Southern Paul, Parkin IP (2014) Organic-inorganic hybrid materials: nanoparticle containing organogels with myriad applications. Chem Commun 50:14418-14420

Ryabchenko KV, Yanovska ES, Tertykh VA, Kichkiruk OYu, Sternik D (2014) Adsorption properties of vermiculite with in situ immobilized polyaniline with respect to $\mathrm{Cr}(\mathrm{VI}), \mathrm{Mo}(\mathrm{VI}), \mathrm{W}(\mathrm{VI}), \mathrm{V}(\mathrm{V})$ and $\mathrm{P}(\mathrm{V})$ anions. Adsorpt Sci Technol 32(1):88-99

Ryabchenko K, Yanovska E, Melnyk M, Sternik D, Kichkiruk O, Tertykh V (2016) Adsorption properties of bentonite with in situ immobilized polyaniline towards anionic forms of $\mathrm{Cr}(\mathrm{VI})$, Mo(VI), W(VI), V(V). Mater Sci (Medžiagotyra) 22(2):249-255

Sapurina I, Stejskal J (2008) The mechanism of the oxidative polymerization of aniline and the formation of supramolecular polyaniline structures. Polym Int 57:295-1325

Skopenko V, Savranskij L (2004) Coordination chemistry. Lybid, Kyiv

Smith AL (1982) Applied IR spectroscopy. Mir, Moscow

Sowa I, Pizoń M, Świeboda R, Kocjana R, Zajdel D (2012) Properties of chelating sorbent prepared by modification of silica gel with polyaniline and acid alizarin violet N. Sep Sci Technol 8:1194-1198

Tamaki R, Naka K, Chujo Y (1997) Synthesis of polystyrene/silica gel polymer hybrids by in situ polymerization method. Pol Bull 39:303-310

Tarasevich BN (2012) IR spectra of the basic classes of organic compounds. Reference materials. MSU, Moscow

Wan Ngah WS, Teong LC, Wong CS, Hanafiah MAKM (2012) Preparation and characterization of chitosan-zeolite composites. J Appl Polym Sci 125:2417-2425

Yang M, Gao Y, He JP, Li HM (2007) Preparation of polyamide 6/silica nanocomposites from silica surface initiated ring-opening anionic polymerization. Express Polym Lett 7:433-442

Yanovska E, Tertykh V, Kichkiruk O, Dadashev A (2007) Adsorption and complexing properties of silicas with analytical reagents grafted via the Mannich reaction. Adsorpt Sci Technol 1-2:81-87

Yanovska E, Savchenko I, Sternik D, Kychkiruk O, Ol'khovik L, Buriachenko I (2017) In situ immobilization on the silica gel surface and adsorption capacity of poly[N-(4-carboxyphenyl) methacrylamide] on toxic metal ions. Nanoscale Res Lett 12:313-331

Zaitsev V (1997) Complexing silica: synthesis, structure of the graft layer and surface chemistry. Folio, Kharkov

Publisher's Note Springer Nature remains neutral with regard to jurisdictional claims in published maps and institutional affiliations. 